\title{
Phaeomelanin matters: redness associates with inter-individual differences in behaviour and hormone profiles in male Scops owls (Otus scops)
}

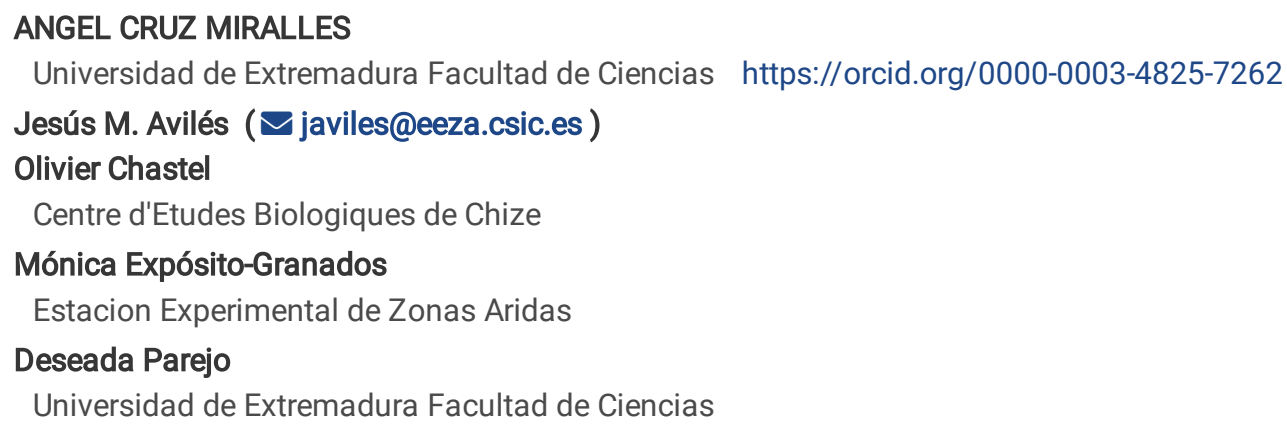

Keywords: Otus scops, syndrome, corticosterone, phenotypic integration, plumage colour, phaeomelanin

Posted Date: February 24th, 2020

DOI: https://doi.org/10.21203/rs.2.24256/v1

License: (c) (i) This work is licensed under a Creative Commons Attribution 4.0 International License. Read Full License 


\section{Abstract}

Background: Individuals within populations often show consistent variation in behavioural and physiological traits, which are frequently inter-correlated, potentially leading to phenotypic integration. Understanding the mechanisms behind such integration is a key task in evolutionary ecology, and melanism has been suggested to play a pivotal role. In birds, most of plumage colour variation is determined by two types of melanin, eumelanin and phaeomelanin, but the role of melanin in avian phenotype integration has mostly been analysed in relation to eumelanin. Here we test for covariation between phaeo-melanin-based coloration, behavioural traits (i.e. nest territoriality, response against researchers, breath rate and parental behaviour) and corticosterone profiles in the polymorphic scops owl Otus scops, a bird species in which more phaeomelanic individuals display reddish colorations.

Results: In males, we observed differences between red and grey individuals in latency to return to the nest after being disturbed and in feather CORT. Reddish males took longer to return to their nests and showed higher levels of feather CORT than grey ones. Behaviour and CORT profiles did not differ between red and grey females.

Conclusions: The found associations between redness, behaviour and CORT in males, but not in females, might suggest the existence of a sex-specific integrated phaeomelanic phenotype, likely due to pleiotropy, in scops owls.

\section{Background}

Individuals within animal populations often differ in behaviour and physiology $(1,2)$, and, frequently, variation in these traits correlate, so that they can be integrated into a complex phenotype (3). Phenotypic integration may reflect genetic, developmental or functional interactions between traits (3), and, because natural selection does not act on isolated traits, may have important consequences for the evolution of phenotypes in natural populations (4). Understanding the mechanisms behind phenotypic integration is a key task in evolutionary and behavioural ecology research $(5,6)$, and melanism has been suggested to play a key role in this phenomenon (7-10).

Melanins are the pigment responsible for most non-structural brown, black and grey colour variation in vertebrates $(11,12)$, and their variation frequently associates with that in morphological, physiological, behavioural and life-history traits in a variety of taxa (reviewed in $(7,13,14)$ ). Birds constitute an ideal system for the study of phenotypic integration in relation to melanism because plumage colour variation is determined in many instances by melanin (either eumelanin (responsible for grey-black colorations) or phaeomelanin (determining reddishbrown colour variation) (15-17)).

In most species so far analysed both types of melanin have been found in the same feathers (18-20), although the bulk of studies about phenotypic integration either do not differentiate between eumelanin and phaeomelanin or just refer to the role of eumelanin (e.g. (7), but see $(8,21))$. This might be unfortunate because, based on the assumption that the triggering of eumelanogenesis is at the expenses of phaeomelanogenesis (7), phaeomelanin and eumelanin colours have contrary expectations regarding their possible associations with other functional traits (22-25). Other studies, however, report results suggesting that the syntheses of one type of melanin would not reduce or block the synthesis of the other (8), pointing to more complex mechanisms generating melanin plumage colour variation (26). In this context, it seems critical to study the role of phaeomelanic-based colours to achieve a full understanding of the role of melanins in promoting covariation among functional traits.

Covariation between phaeomelanic plumage coloration and other traits may arise due to the cost of production of phaeomelanin (conditiondependence hypothesis). A growing number of studies provide support for the idea that phaeomelanic plumage colours may function as honest signals of quality of the bearer which are constrained by physiological trade-offs or social interactions (reviewed in (27-29)). The synthesis of phaeomelanin depends on the amount of cysteine and glutathione. Glutathione plays a critical role protecting cells from oxidative damages, as a nutrient metabolism or in regulating immune function (30). Hence, there could be a physiological trade-off between anti-oxidative defence and the expression of phaeomelanin, so that only the best individuals would be able to display the reddest phenotypes (31). Based on these production costs, it has been suggested that phaeomelanic colorations would have a higher potential to evolve as honest signals of quality than eumelanic ones (25). Alternatively, trait covariation with phaeomelanic coloration could be due to pleiotropic effects of genes, either by genes involved in phaeomelanogenesis or in hormones synthesis (pleiotropy hypotheses) (32). The melanocortin system comprises a set of five membrane receptors (MCRs) which regulate several functions as melanogenesis, sexual behaviour, aggressiveness, and stress response among others, depending of the binding of melanocortins and the agouti signalling protein (ASIP) (7). The binding of the melanocortins to the receptor MC1R (coded by melanocortin-1 receptor gene) promotes eumelanin synthesis, whereas the binding of ASIP to MC1R would promote the formation of phaeomelanin $(33,34)$. As melanocortins also bind to other MCRs than MC1R that regulate behaviour (e.g. MC5R, aggressiveness) and physiology (e.g. MC2R, HPA stress response), this may result in covariation (7). Alternatively, a number of mechanisms in which hormones are involved (e.g. changes in hormone secretion, hormonal affinity for carrier proteins, rates of degradation and conversion, and interaction with target tissues) could potentially coordinate the co-expression of 
behavioural, physiological and morphological traits leading to covariation (hormonal pleiotropy sensu (35)). In particular, corticosterone (CORT hereafter), a glucocorticoid widely investigated in birds that affects the response to stress through the activation of hypothalamuspituitary-adrenal (HPA) axis, might play such a modulator role since it has been profusely linked with behaviour (36-39) and melanism (4042). Whichever the exact mechanism promoting covariation between phaeomelanin pigment and other traits, which is far of our scope here, very few studies have yet analyses how phaeo- rather than eu-melanin colorations integrate with other phenotypic characters.

Here we study across-years covariation between phaeomelanic plumage colour, behaviours (territoriality, behaviour during researcher visits and parental care) and stress response (breath rate and CORT profiles) in male and female adult Eurasian scops owls (Otus scops) (scops owl hereafter). In scops owls, feathers contain eumelanin and phaeomelanin, but most of the redness variation is due to the amount of phaeomelanin pigment (43). Moreover, in this species colour does not change with age (44), making this an ideal system to study the specific role of phaeomelanin based colours in trait covariation. Based on the assumption that the synthesis of phaeomelanin blocks the synthesis of eumelanin $(23,45)$, we predict that 1 ) reddish individuals should exhibit reactive behaviours and thus be less territorial and show lower anti-predator behaviour than more greyish ones. For those behaviours measured in different periods of the day (i.e. response of females against researchers), this prediction, should be assessed considering the time of day because different colour morphs could have different sleep activity during the day (e.g. in mammals (46), in birds (47)). Concerning the relationship between colour and CORT we predict 2) that reddish individuals would be more sensitive to stressful factors and, hence, that they would have higher levels of corticosterone in plasma and feathers. Finally, because behaviour could be subjected to sex-specific selection (35), and, hormonal pathways could differ between sexes due to sexual hormones $(48,49)$, we predict 3$)$ sex-specific differences in the relationships between colour, behaviour and CORT profiles.

\section{Results}

Latency of hooting response of males to territorial intrusions was marginally repeatable $\left(r=0.45 ; F_{7,9}=2.75\right.$, $\left.P=0.08\right)$, but not so duration of hooting response $\left(r=0.23 ; F_{11,12}=1.59, P=0.22\right)$. Therefore, duration of response to territorial intruders was disregarded in subsequent analyses. By contrast, breath rate was repeatable $\left(r=0.31 ; F_{27,43}=2.16, P=0.01\right)$.

Behavioural traits versus coloration

Latency of hooting to the playback of a male intruder was not explained by male's coloration (Table 1).

Table 1

Results of the statistical model analysing male territoriality in scops owls as latency of response against an intruder in relation to plumage coloration

( $N=30$ individuals). Significant terms are depicted in bold. Full results including Beta estimates and standard errors are shown in the Table 2 of the appendix.

\begin{tabular}{|lllllll|}
\hline & \multicolumn{3}{l}{ Saturated model } & \multicolumn{3}{l|}{ Reduced model } \\
\hline Explanatory term & $\mathrm{F}$ & $\mathrm{df}$ & $\mathrm{P}$ & $\mathrm{F}$ & $\mathrm{df}$ & $\mathrm{P}$ \\
\hline Male colourkYear & 0.66 & 4,17 & 0.628 & & & \\
\hline Male colour & 1.47 & 1,17 & 0.241 & & & \\
\hline Year & 0.64 & 4,17 & 0.644 & & & \\
\hline Female colour & 0.76 & 1,17 & 0.397 & 3.50 & 1,28 & 0.072 \\
\hline Date & 0.33 & 1,17 & 0.571 & & & \\
\hline Brood size & 0.01 & 1,17 & 0.940 & & & \\
\hline
\end{tabular}

Females' response to researchers' visits tended to depend on plumage colour in interaction with the hour of the day, but the pattern vanished when the model was reduced (Table 2). 
Table 2

Results of the statistical models analysing response of females to researchers $(\mathrm{N}=47$ individuals) and breath rate in male ( $\mathrm{N}=35$ individuals) and female ( $\mathrm{N}=52$ individuals) scops owls in relation to coloration. Significant terms are depicted in bold. Full results including Beta estimates and standard errors are shown in the Table 3 of the appendix.

\begin{tabular}{|c|c|c|c|c|c|c|c|c|c|c|c|c|c|}
\hline \multirow[b]{3}{*}{$\begin{array}{l}\text { Dependent } \\
\text { variable }\end{array}$} & \multirow[b]{3}{*}{$\begin{array}{l}\text { Explanatory } \\
\text { term }\end{array}$} & \multicolumn{6}{|l|}{ Males } & \multicolumn{6}{|l|}{ Females } \\
\hline & & \multicolumn{3}{|c|}{ Saturated model } & \multicolumn{3}{|c|}{ Reduced model } & \multicolumn{3}{|c|}{ Saturated model } & \multicolumn{3}{|c|}{ Reduced model } \\
\hline & & Statistic & df & $P$ & Statistic & $\mathrm{df}$ & $\mathrm{P}$ & Statistic & $\mathrm{df}$ & $P$ & Statistic & $d f$ & $\mathrm{P}$ \\
\hline \multirow[t]{6}{*}{$\begin{array}{l}\text { Response to } \\
\text { researcherst }\end{array}$} & Colour*Hour & - & - & - & & & & $\begin{array}{l}x 2= \\
3.34\end{array}$ & 1 & 0.068 & & & \\
\hline & Colour & - & - & - & & & & $\begin{array}{l}\times 2= \\
3.58\end{array}$ & 1 & 0.058 & & & \\
\hline & Hour & - & - & - & & & & $\begin{array}{l}x 2= \\
2.32\end{array}$ & 1 & 0.128 & & & \\
\hline & Year & - & - & - & & & & $\begin{array}{l}x 2= \\
1.85\end{array}$ & 5 & 0.174 & & & \\
\hline & Date & - & - & - & & & & $\begin{array}{l}x 2= \\
8.91\end{array}$ & 1 & 0.113 & $\begin{array}{l}x 2= \\
1.76\end{array}$ & 1 & 0.185 \\
\hline & Brood size & - & - & - & & & & $\begin{array}{l}\times 2= \\
1.12\end{array}$ & 1 & 0.290 & & & \\
\hline \multirow[t]{6}{*}{ Breath rate } & Colour*Year & $F=0.52$ & $\begin{array}{l}3 \\
21\end{array}$ & 0.673 & & & & $F=0.78$ & $\begin{array}{l}3 \\
24\end{array}$ & 0.5154 & & & \\
\hline & Colour & $F=0.01$ & $\begin{array}{l}1 \\
21\end{array}$ & 0.942 & & & & $F=0.03$ & $\begin{array}{l}1 \\
24\end{array}$ & 0.8552 & & & \\
\hline & Year & $F=0.36$ & $\begin{array}{l}3 \\
21\end{array}$ & 0.782 & & & & $F=0.57$ & $\begin{array}{l}3 \\
24\end{array}$ & 0.642 & & & \\
\hline & $\begin{array}{l}\text { Partner } \\
\text { colour }\end{array}$ & $F=1.00$ & $\begin{array}{l}1 \\
21\end{array}$ & 0.329 & & & & $F=0.40$ & $\begin{array}{l}1 \\
24\end{array}$ & 0.534 & & & \\
\hline & Date & $F=0.15$ & $\begin{array}{l}1 \\
21\end{array}$ & 0.702 & & & & $F=0.00$ & $\begin{array}{l}1 \\
24\end{array}$ & 0.998 & & & \\
\hline & Brood size & $F=1.19$ & $\begin{array}{l}1 \\
21\end{array}$ & 0.288 & $F=2.95$ & $\begin{array}{l}1 \\
33\end{array}$ & 0.095 & $F=0.53$ & $\begin{array}{l}1 \\
24\end{array}$ & 0.472 & $F=1.48$ & $\begin{array}{l}1 \\
49\end{array}$ & 0.229 \\
\hline
\end{tabular}

Breath rate was not related with plumage coloration neither in male nor in females (Table 2).

Parental care versus coloration

Latency to enter the nest-box differed for males, but not for females, of different colour score (Table 3). The pattern remains when the model was based on the comparison between greyish and reddish individuals only (Table 3). So that after setting the camera, time to resume feeding of reddish males took longer than that of more greyish males (Table 3 and Fig. 1). However, feeding rates of female and male scops owls did not differ between different colour morphs (Table 3). 
Table 3

Results of statistical models analysing parental care (i.e. latency ( $\mathrm{N}=39$ for females and $\mathrm{N}=65$ for males) and feeding rate ( $\mathrm{N}=69$ for females and $\mathrm{N}=69$ for females)) in relation to plumage coloration score or categorized as greyish and reddish individuals. Significant terms are depicted in bold. Full results including Beta estimates and standard errors are shown in the Table 4 of the appendix.

\begin{tabular}{|c|c|c|c|c|c|c|c|c|c|c|c|c|c|}
\hline \multirow[b]{3}{*}{$\begin{array}{l}\text { Dependent } \\
\text { variable }\end{array}$} & \multirow[b]{3}{*}{$\begin{array}{l}\text { Explanatory } \\
\text { term }\end{array}$} & \multicolumn{6}{|c|}{ Males } & \multicolumn{6}{|c|}{ Females } \\
\hline & & \multicolumn{3}{|c|}{ Saturated models } & \multicolumn{3}{|c|}{ Reduced models } & \multicolumn{3}{|c|}{ Saturated models } & \multicolumn{3}{|c|}{ Reduced models } \\
\hline & & $\mathrm{F}$ & $\mathrm{df}$ & $\mathrm{P}$ & $\mathrm{F}$ & df & $P$ & $\mathrm{~F}$ & $\mathrm{df}$ & $\mathrm{P}$ & $\mathrm{F}$ & df & $\mathrm{P}$ \\
\hline \multicolumn{14}{|l|}{ Colour score } \\
\hline \multirow[t]{8}{*}{ Latency } & Colour*Year & 1.26 & $\begin{array}{l}5 \\
46\end{array}$ & 0.296 & & & & 0.12 & $\begin{array}{l}5 \\
23\end{array}$ & 0.974 & & & \\
\hline & Colour & 0.39 & $\begin{array}{l}1 \\
46\end{array}$ & 0.535 & 6.15 & $\begin{array}{l}1 \\
60\end{array}$ & 0.016 & 0.57 & $\begin{array}{l}1 \\
23\end{array}$ & 0.457 & & & \\
\hline & Year & 0.38 & $\begin{array}{l}6 \\
46\end{array}$ & 0.890 & & & & 0.07 & $\begin{array}{l}5 \\
23\end{array}$ & 0.991 & & & \\
\hline & Brood size & 3.59 & $\begin{array}{l}1 \\
46\end{array}$ & 0.064 & 7.45 & $\begin{array}{l}1 \\
60\end{array}$ & 0.008 & 0.32 & $\begin{array}{l}1 \\
23\end{array}$ & 0.577 & & & \\
\hline & Partner colour & 0.03 & $\begin{array}{l}1 \\
46\end{array}$ & 0.873 & & & & 0.7 & $\begin{array}{l}1 \\
23\end{array}$ & 0.412 & & & \\
\hline & Date & 2.63 & $\begin{array}{l}1 \\
46\end{array}$ & 0.112 & & & & 4.87 & $\begin{array}{l}1 \\
23\end{array}$ & 0.038 & 7.55 & $\begin{array}{l}1 \\
37\end{array}$ & 0.009 \\
\hline & Hour & 0.00 & $\begin{array}{l}1 \\
46\end{array}$ & 0.984 & & & & 2.2 & $\begin{array}{l}1 \\
23\end{array}$ & 0.151 & & & \\
\hline & $\begin{array}{l}\text { Record } \\
\text { duration }\end{array}$ & 0.11 & $\begin{array}{l}1 \\
46\end{array}$ & 0.738 & & & & 0.44 & $\begin{array}{l}1 \\
23\end{array}$ & 0.514 & & & \\
\hline \multicolumn{14}{|c|}{ Greyish vs Reddish } \\
\hline \multirow[t]{8}{*}{ Latency } & Colour*Year & 0.19 & $\begin{array}{l}4 \\
22\end{array}$ & 0.940 & & & & - & - & - & & & \\
\hline & Colour & 0.8 & $\begin{array}{l}1 \\
22\end{array}$ & 0.380 & 4.60 & $\begin{array}{l}1 \\
35\end{array}$ & 0.039 & - & - & - & & & \\
\hline & Year & 0.43 & $\begin{array}{l}5 \\
22\end{array}$ & 0.824 & & & & - & - & - & & & \\
\hline & Brood size & 3.09 & $\begin{array}{l}1 \\
22\end{array}$ & 0.093 & 11.64 & $\begin{array}{l}1 \\
35\end{array}$ & 0.002 & - & - & - & & & \\
\hline & Partner colour & 0.54 & $\begin{array}{l}1 \\
22\end{array}$ & 0.469 & & & & - & - & - & & & \\
\hline & Date & 0.02 & $\begin{array}{l}1 \\
22\end{array}$ & 0.884 & & & & - & - & - & & & \\
\hline & Hour & 0.04 & $\begin{array}{l}1 \\
22\end{array}$ & 0.843 & & & & - & - & - & & & \\
\hline & $\begin{array}{l}\text { Record } \\
\text { duration }\end{array}$ & 0.02 & $\begin{array}{l}1 \\
22\end{array}$ & 0.887 & & & & - & - & - & & & \\
\hline \multirow[t]{4}{*}{ Feeding rate } & Colour*Year & 0.51 & $\begin{array}{l}5 \\
49\end{array}$ & 0.767 & & & & 0.31 & $\begin{array}{l}5 \\
49\end{array}$ & 0.907 & & & \\
\hline & Colour & 0.02 & $\begin{array}{l}1 \\
49\end{array}$ & 0.900 & & & & 0.16 & $\begin{array}{l}1 \\
49\end{array}$ & 0.688 & & & \\
\hline & Year & 0.49 & $\begin{array}{l}5 \\
49\end{array}$ & 0.781 & & & & 0.24 & $\begin{array}{l}5 \\
49\end{array}$ & 0.942 & & & \\
\hline & Brood size & 3.98 & $\begin{array}{l}1 \\
49\end{array}$ & 0.052 & 9.38 & $\begin{array}{l}1 \\
66\end{array}$ & 0.003 & 1.09 & $\begin{array}{l}1 \\
49\end{array}$ & 0.303 & & & \\
\hline
\end{tabular}




\begin{tabular}{|c|c|c|c|c|c|c|c|c|c|c|c|c|}
\hline & Males & & & & & & Females & & & & & \\
\hline Partner colour & 0.05 & $\begin{array}{l}1 \\
49\end{array}$ & 0.833 & & & & 0.00 & $\begin{array}{l}1 \\
49\end{array}$ & 0.954 & & & \\
\hline Date & 3.11 & $\begin{array}{l}1 \\
49\end{array}$ & 0.084 & & & & 0.79 & $\begin{array}{l}1 \\
49\end{array}$ & 0.377 & & & \\
\hline Hour & 2.6 & $\begin{array}{l}1 \\
49\end{array}$ & 0.113 & 8.26 & $\begin{array}{l}1 \\
66\end{array}$ & 0.005 & 0.02 & $\begin{array}{l}1 \\
49\end{array}$ & 0.900 & & & \\
\hline $\begin{array}{l}\text { Record } \\
\text { duration }\end{array}$ & 0.89 & $\begin{array}{l}1 \\
49\end{array}$ & 0.351 & & & & 0.97 & $\begin{array}{l}1 \\
49\end{array}$ & 0.33 & 4.72 & $\begin{array}{l}1 \\
67\end{array}$ & 0.033 \\
\hline
\end{tabular}

Corticosterone profile versus coloration

Stress-induced blood CORT level of females did not differ with plumage colour (Table 4). However, differences in feather CORT in relation to colour depended on sex (Table 4): reddish males show higher levels of feather CORT than that of more greyish males $(\mathrm{P}=0.01)$, whereas feather CORT levels did not vary in relation to colour morph in females $(P=0.33$, Fig. 2$)$. 
Table 4

Results of two GLMs to analyse levels of CORT in blood for females ( $N=28$ individuals) and CORT in feathers for both sexes $(\mathrm{N}=70)$ as dependent variables in relation to individual coloration score or categorized as greyish and reddish individuals. Significant terms are depicted in bold. Full results including Beta estimates and standard errors are shown in the Table 5 of the appendix.

\begin{tabular}{|c|c|c|c|c|c|c|c|}
\hline \multirow[b]{2}{*}{ Dependent variable } & \multirow[b]{2}{*}{ Explanatory terms } & \multicolumn{3}{|c|}{ Saturated models } & \multicolumn{3}{|c|}{ Reduced models } \\
\hline & & $\mathrm{F}$ & $d f$ & $P$ & $\mathrm{~F}$ & df & $P$ \\
\hline \multirow[t]{6}{*}{ Females blood stress-induced CORT } & Colour*Year & 0.17 & 2,9 & 0.844 & & & \\
\hline & Colour*Hour & 0.98 & 1,9 & 0.349 & & & \\
\hline & Colour & 1.41 & 1,9 & 0.265 & & & \\
\hline & Year & 0.19 & 2,9 & 0.829 & 3.93 & 2,25 & 0.033 \\
\hline & Date & 0.55 & 1,9 & 0.478 & & & \\
\hline & Hour & 0.95 & 1,9 & 0.354 & & & \\
\hline \multicolumn{8}{|l|}{ Colour score } \\
\hline \multirow[t]{7}{*}{ CORT in feathers } & Colour*Sex*Year & 0.26 & 2,53 & 0.769 & & & \\
\hline & Colour*Sex & 6.64 & 1,53 & 0.013 & 8.27 & 1,64 & 0.006 \\
\hline & Colour*Year & 0.37 & 3,53 & 0.772 & & & \\
\hline & Sex*Year & 0.31 & 2,53 & 0.735 & & & \\
\hline & Colour & 1.08 & 1,53 & 0.304 & 2.04 & 1,64 & 0.158 \\
\hline & Year & 0.55 & 3,53 & 0.651 & & & \\
\hline & Sex & 5.33 & 1,53 & 0.025 & 6.24 & 1,64 & 0.015 \\
\hline \multicolumn{8}{|l|}{ Greyish vs Reddish } \\
\hline \multirow[t]{7}{*}{ CORT in feathers } & Colour*Sex*Year & 0.01 & 2,33 & 0.988 & & & \\
\hline & Colour*Sex & 9.03 & 1,33 & 0.005 & 8.17 & 1,44 & 0.007 \\
\hline & Colour*Year & 1.44 & 3,33 & 0.248 & & & \\
\hline & Sex*Year & 0.61 & 3,33 & 0.612 & & & \\
\hline & Colour & 1.32 & 1,33 & 0.258 & 1.89 & 1,44 & 0.177 \\
\hline & Year & 1.95 & 3,33 & 0.140 & & & \\
\hline & Sex & 0.75 & 1,33 & 0.393 & 3.19 & 1,44 & 0.081 \\
\hline
\end{tabular}

\section{Discussion}

Our results tentatively support the existence of a phaeomelanic syndrome in male scops owls. First, feather CORT profiles differed with redness so that the reddish males had consistently higher values than grey ones. On the other hand, in males, we found that reddish individuals were more reactive after researchers' visits to nests than greyish ones. Females differing in colour did not differ in their behaviour and CORT profiles. Below we discuss the most likely explanations for the causes and sense of patterns based on current knowledge about the role of phaeomelanin and corticosterone in determining phenotypic variation.

Causes of differences in behaviour and CORT profiles in relation to colour morph

Male scops owls showed consistent individual variation in return to their nests after being disturbed by research activity explained by phaeomelanic colour. Reddish males took longer to resume their feed provision into the nest. These pattern does not depend on the years analysed, suggesting that differences between colour morphs would not be affected by environmental conditions. However, it cannot be discarded that the range of environmental conditions considered here (five to seven years) was not large enough to modify the associations between phaeomelanic colour and behaviours. 
One possibility to explain consistency of colour-behaviour patterns in males would be provided by the melanocortin hypothesis (7). Due to the membrane receptors (MCRs) could regulate functions as melanogenesis, sexual behaviour, aggressiveness, and stress response (7). Although we report here an association between phaeomelanic colour and territorial behaviour in male scops owls, we recently have found that variation in the coding sequence of the MC1R does not explain variation in redness in this species (43). However, more than 150 genes have been identified to be involved in coloration and/or pattern designs in animals, and many of them could be involved in phaeomelanins synthesis (22). Hence, we can only discard a pleiotropic effect of MC1R but not of other genes potentially involved in melanogenesis such as MIFT, ASIP, TYR, SLC45A2 and TYRP1 (e.g. (68-71)).

Alternatively, colour-behaviour patterns in males could be due to the pleiotropic effect of genes regulating the expression of stress hormones as the corticosterone (32). We found that reddish males have higher levels of CORT in feathers than more greyish ones through the study years, which may suggest that individuals differing in phaeomelanic colour have a different sensitivity to stress during the moult period. However, we did not find any relationship between breathing rate (i.e. a proxy of handling stress) and phaeomelanic colour in males. Given that feather CORT is likely to reflect the accumulated stress during the time of feather growth (57), it is also possible that the pattern arose due to the fact that males differing in coloration faced different stressors during moult time (i.e. moulting at different time or places or following a different moult pattern (e.g. (72)). A particularly fruitful field of future research which may help to disentangle these possibilities would be to study how individuals differing in phaeomelanic colour use space and time outside the breeding season by deploying GPS devices in combination with the study of stress-induced plasma CORT which likely reflects the instantaneous level of response to stress.

The relationships between phaeomelanic colours and other functional traits seemed to differ between sexes, a pattern that has already been reported for eumelanic colorations (e.g. common buzzard Buteo buteo; (73); marsh harrier Circus aeruginosus; (74); masked boby Sula dactylatra (8)). Sexual differences in covariation could arrive from variation in the relative role of eumelanin versus phaeomelanin influencing trait expression in the two sexes. However, pigment analyses have revealed no sexual differences in the relative importance of the two melanin pigments in scops owls (43). Contrary to what happened in males, CORT profiles were not associated with coloration in females, a pattern that does not depend on the study year. The different patterns found between phaeomelanin colours and CORT profiles in females and males may be due to sex-specific hormonal pathways due to the interference with sexual hormones. Indeed, levels of testosterone have been reported to negatively correlate with CORT $(48,49)$, whereas oestrogens enhance glucocorticoids responses $(75)$. Also, sexes could show differential sensitivity to hormones in the brain mediated by the abundance of androgen receptors, aromatase or oestrogens $(76,77)$. Alternatively, given that patterns found in males are based on feather CORT, it could be argued that males and females are not under the same stressors when they moult feathers or that they do not moult at the same time.

Sense of covariation between colour morph, behaviour and corticosterone profiles

Our results would support expectations from a key role of mechanisms involved in phaeomelanin synthesis in determining traits associations in male scops owls. Whatever the physiological mechanism behind, the expression of eumelanin and phaeomelanin colours are expected to be inversely related to other functional traits $(22,23,25)$. So far, covariation between eumelanic colours and behaviour has been widely investigated in birds (reviewed in (7)), but only recently a few studies have considered covariation between phaeomelanic colours and behaviour, showing contradictory results $(21,45,63,78)$. First, Van den Brink and co-workers did not detect any relationship between behaviour and the reddish phaeomelanic coloration in both the Eurasian kestrel Falco tinnunculus (78) and the barn owl Tyto alba (45). However, redness was positively associated with antipredator behaviour in tawny owls Strix aluco (63) and barn swallows Hirundo rustica (21). As expected, our results show that reddish scops owl males show more reactive behaviour than more grey ones. Differences among studies might be due to the different relative role of eumelanin versus phaeomelanin in determining coloration and behaviour in different species, a possibility that merits further investigation.

Concerning corticosterone levels, a number of studies have previously investigated their association with eumelanin-based traits in birds and shown that in general darker eumelanic individuals have lower stress-induced CORT levels $((40,41)$, see however (8)). The association of phaeomelanin and the stress response, however, remains elusive. Some studies do not find a significant association between phaeomelanin colorations and circulating basal or stress-induced CORT (North America barn swallows Hirundo rustica erythrogaster, (24) or feather CORT (yellow warblers Setophaga petechia, (79) levels. However, another study in barn swallows shows that darker phaeomelanic males had higher baseline and stress-induced levels of circulating CORT (80). In agreement with expectation from a contrary role of eumelanin and phaeomelanin, we found that reddish scops owl males showed higher levels of feather CORT which may suggest that reddish individuals would be less prepared to cope with stress during moulting. Nevertheless, as above stressed, it is also possible that variation in phaeomelanic colour determined first the behaviour and/or moulting pattern (72), and, as a by-product, the stress response. Limitations of the study

Our study has some weaknesses worth mentioning that may affect the strength of our conclusions. First, due to logistic issues during data collection, we did not study multiple trait covariation, but independent pair-wise covariation. This limits our potential to conclude about 
complete phenotype integration in scops owls, and it remains to be studied if the found patterns in relation to colour morphs form part of a higher level of integration. Second, given huge differences in reproductive behaviours between sexes, we could not measure the same behaviours nor estimate CORT profiles in the same way in males and females. Future studies aiming to investigate sex-specific phenotypic integration should ideally target on non-reproductive periods which are less likely affected by sex.

\section{Conclusions}

The found stable relationships between phaeomelanin-based colour, behaviour and CORT profiles in males might suggest the existence of an integrated phaeomelanic phenotype in scops owls. This is one of the first studies showing a role of phaeomelanin underlying the covariation between melanic coloration and other phenotypic traits, urging for more investigation into the genetic basis linking behaviour and stress-related hormones with the production of this pigment. Finally, although we have found sex-specific covariation among functional traits, our work identifies practical difficulties to study phenotype integration in the reproductive period, where selective pressures for the functional association among behaviour, endocrine profile, and coloration might differ between sexes.

\section{Methods}

Study system

The study was performed from 2012 to 2018 in the Hoya of Guadix-Baza, Granada, southeast of Spain ( $\left.37^{\circ} 18^{\prime} \mathrm{N}, 3^{\circ} 11^{\prime} \mathrm{W}\right)$. The area is an extensive agricultural landscape with scattered holm oaks (Quercus ilex) where cork-made nest-boxes have been set up to palliate the low density of natural holes and favour the reproduction of medium sized hole-nesting birds (see details in (50)).

The scops owl is a medium-sized nocturnal and trans-Saharan migrant owl arriving into the study area in April $(51,52)$ and starting its reproduction throughout May (52). Scops owls make one clutch per year of about 2-6 eggs that are laid every 1-3 days. Females start incubating after laying the second egg, and incubation takes 24-25 days (53). Nestling rearing takes 21-29 days on average (51).

\section{Sampling procedure}

Every year, starting at the last week of April, nest-boxes are visited once a week until egg-laying is detected. After detection of a breeding attempt, nests are visited once more after the end of laying, and only once again just before the estimated hatching date to avoid nest desertion. After owlet hatching, nests are visited weekly to record reproductive parameters.

Capture of adults for this study was done by hand, while sleeping at nests in the case of incubating females, and, in the case of males, with nest-traps while they were delivering food to offspring (44). This capture methodology has a negligible effect on nest desertion in this species (44). All individuals were metal ringed and sexed based on inspection of the brood patch (only present in females). Moreover, upon capture, all adults were photographed for colour assignment, blood samples extracted and feathers collected for assessment of corticosterone profile and some of the behavioural traits measured (see below).

\section{Colour characterization}

We systematically took two standardized photos for each captured individual: one head-on, in which we could observe head and breast plumage; and other to the back part in which we observed the back and wings. Photographs were taken using a digital camera (Canon EOS 1300D, Lens: EF-S 18-55 IS II) mounted on a tripod at a constant distance of $50 \mathrm{~cm}$ and with a flash (aperture: 4.5, shutter speed: 1/200, ISO: 800). Owls were gently fixed with a harness inside a neutral-coloured box that ensured stable light conditions and with the head placed next to a colour chart (X-Rite ColorChecker ${ }^{\circledR}$ Passport). Photos were standardized using the Adobe ${ }^{\circledR}$ Photoshop Lightroom 6 plugin and used to determine coloration by focusing on redness extension at the head, breast and wings-back. Each body part was scored among 1 to 3 points depending if they were predominantly greyish or reddish (44). Previous results have shown that scores of the three body parts are highly correlated within individuals and that scores assigned by different observers on the same individual are highly repeatable (44), hence scores of the three body parts were summed to get an individual score for every bird (ranging from 3 to 9 ). Based on this scores owls are classified as grey, intermediate and brown given that the frequency of scores is trimodal in our population (44). Pigment analyses have revealed that although eumelanin is the most abundant pigment in scops owl feathers, redness is related to phaeomelanin: the higher the score the larger the amount of phaeomelanin pigment in head and breast feathers (43). However, most of variation in phaeo-melanin content in head and breast feathers occurs between brown and grey morphs, and not between these two morphs and the intermediate one (43). Hence, in a first step we use colour scores in a continuous way to characterize variation in plumage coloration of scops owls, but also compare between grey and brown morphs (i.e. excluding intermediate individuals) to address the specific role of phaeomelanin-based colour variation.

Behavioural traits 
Territoriality was measured in 30 males from 2014 to 2018 by recording behavioural responses to a simulated territorial intrusion made by broadcasting calls of foreign males near the nest. All trials were conducted when clutches were completed and between nightfall and 01:00 a.m., when owls were expected to be more active. Territorial intrusions were simulated by broadcasting calls of a male scops owl with a MP3 player (takeMS MP3 Player “Deseo") connected to a speaker (MOLGAR 3" 20W 4 ohm) placed under the closest tree to the target nest. Broadcasted records consisted of an initial 2 minutes silent track as an acclimation period, followed with a 2 minutes track with male territorial calls followed by, another 10 minutes of silence track and a final territorial call track of 2 minutes of the same male. To avoid recognition by familiarity, territorial tracks came from 3 unknown males to our population that were randomly chosen for each territorial intrusion simulation. Territorial tracks were extracted from xeno-canto (https://www.xeno-canto.org/). Male territorial behaviour was measured using two different variables: 1) Latency of response to the playback was measured as the time in seconds from broadcasting to the first male hooting response; 2) Duration of response to the playback, measured as time lasted in seconds from the first to the last male hooting response.

To confirm that individuals responding to the playback were the owners of the territory and not neighbours or floaters, 9 breeding males were captured and deployed with radio transmitters tags (PIP Ag392 de Biotrack Ltd., Wareham, UK) the night before the intrusion experiment in 2016. Tags with a weight of 1.10-1.90 g, were attached with cyanoacrylate glue onto the feathers of the back which is below the $2.5 \%$ of the adults' weight threshold suggested by Rodríguez_Ruiz et al. (54). Individuals were located by means of receivers Yaesu FT-290R II antennas (frequency range of $150 \mathrm{MHz}$ ). All the individuals hooting back to the simulated intrusion carried the transmitter suggesting that they were the owners of the territory. The 9 males were re-captured the night after the experiment to remove the tag without any apparent harmful effect. None of the nests owned by these males were abandoned after tag deployment.

Female response to researchers' visits

Response to researchers was measured in 47 females based on standardized video recordings (video camera Sony DCR-SR32) made at the nest boxes during the day, when females usually sleep. Behaviour was recorded during 20 seconds inside the nest box after the careful opening of the roof, while slowly approaching the camera to the female, and 10 seconds more while holding it in the observers' hand after its capture. From the recordings, females were classed in two different categories: When females clicked the beak, hissed, swelled their body, laid on their back with claws raised, grabbed with bill or claws and/or tried to get away through that 30 seconds, were classified as proactive. Females feigning death in the nest and in the hand and not exhibiting any aggressive behaviour were classified as reactive.

Breath rate

Breath rate, estimated as the number of breast movements during 30 seconds, was measured from 2015 to 2018 in 63 females and 44 males as a measure of individual response to handling stress (55).

Parental care

We measured parental provisioning in most scops owl nests from 2012 to 2018 (98 nests) at the beginning of the chick-rearing period (3 days after the hatching of the last egg). Parental activity inside nest-boxes was recorded at night for at least 60 minutes using infrared cameras (KPC- S500, black and white CCD camera, Esentia Systems Inc.). Upon capture females were marked with a white Tippex spot on the head that allowed their identification in recordings. In subsequent visits to the nests and in video recordings we did not find any apparent effect of these marks on females.

From recordings, we determined: 1) latency of entering the nest-box in minutes after setting the microcamera, and, 2) adults' feeding rates as the number of prey per hour.

Repeatability of behaviour

Our study design, where individuals were not assayed several times for the same behaviour in the same context (either because many birds do not return into our population from one year to another; or because the number of individuals with repeated observations varied according to the behaviour analysed due to logistic problems), does not allow providing a sound test for individual repeatability in behaviour (56). To account for this potential limitation, we measured repeatability in those individuals in which we had measured the same behavioural trait in more than one year (male territoriality $n=15$; breath rate, males $=15$ and females $=11$ ). Repeatability of female response to researchers' visits was not analysed because in the few repeated females the trait was measured in every individual in different hours of the day potentially conditioning the test. Moreover, parental repeatability was not estimated either because number of nestlings varied between years, which could have affected this behaviour. Analyses of covariation were subsequently conducted only on repeatable behaviours. We 
are aware that this might have rendered unrealistic low repeatability for these behaviours, and, therefore that our analyses should be considered conservative in this sense. However, we think that this approach is still highly valuable to study phenotypic integration in relation to phaeomelanin coloration because we targeted on evolutionary relevant behaviours for the studied species, rather than focusing on stereotyped behaviours against a stimulus that can hardly be interpreted in the context of reproduction.

Corticosterone levels

Adrenocortical response to stress was determined through stress-induced blood CORT levels and CORT deposited in feathers. In 28 breeding

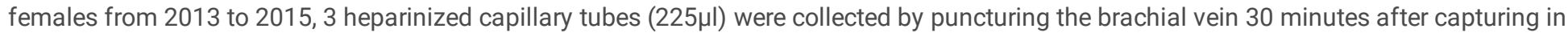
order to measure stress-induced CORT levels. We decided not to measure stress-induced CORT levels in males because we were unsure about the time it took males to enter traps and hence cannot estimate the time in the CORT increase curve in which the blood is extracted. Upon capture, we also collected the third covert feather of the left wing of adult individuals ( 27 males and 43 females) from 2012 to 2015 to determine CORT in feathers. Feathers were kept in hermetic plastic bags until analysis. The two CORT measures reveal different information. Stress-induced CORT reflects individual's physiological state at the instant of sampling, and meanwhile CORT in feathers provides information about longer time periods, because the deposition of CORT in feather parallels its growth (57), showing thus the individual stress during the growing of feathers. Both measures are not correlated for our sample $(r=-0.093, P=0.673, N=23)$. Blood samples were kept in coolers until plasma separation, which were done the same day by centrifugation at $368 \mathrm{~g}$ during 5 minutes. Plasma was stored at $-20^{\circ} \mathrm{C}$ until analyses.

Hormonal analyses were performed by ME at the Centre d'Etudes Biologiques of Chizé, France. Concentration of CORT in plasma samples was determined using an ethyl ether extraction technique following Lormée et al. (58). CORT levels in feathers were estimated using the method described by Bortolotti et al. (57), where a methanol-based extraction technique was used to extract CORT from feathers. Radioimmunoassay was used to measure the CORT extracts of plasma and feathers (58), with a highly cross-reactive rabbit anti-mouse antibody from Sigma (C8784). Different plasma steroids cross-react with the corticosterone antiserum: 11-deoxycorticosterone 20\%, progesterone $15.7 \%$, 20a-hydroxyprogesterone $8.8 \%$, testosterone $7.9 \%$, 20ß-hydroxyprogesterone $5.2 \%$, cortisol $4.5 \%$, aldosterone $4.4 \%$, cortisone $3.2 \%$, androstenedione $2.6 \%$, 17 -hydroxyprogesterone $1.8 \%$, 5 a-dehydrotestosterone $1.4 \%$, androsterone $<0.1 \%$, estrone $<0.1 \%$, estriol $<0.1 \%$. Overnight incubation of the extracts was done with $3 \mathrm{H}$-corticosterone and antiserum at $4^{\circ} \mathrm{C}$. After centrifugation, a liquid scintillation counter was used to count the bound fraction in the aliquots of the extracts. Samples were frozen at $-20^{\circ} \mathrm{C}$ unless they were assayed the same day. The detection limit of the method was $0.28 \mathrm{ng} / \mathrm{mL}$ (lowest measure was $1.23 \mathrm{ng} / \mathrm{mL}$ ). Although CORT in feathers was quantified in $\mathrm{ng} / \mathrm{mL}$, values were transformed to $\mathrm{ng} / \mathrm{mm}$ for which feathers length (without calamus) were previously measured with a calliper to the nearest $0.1 \mathrm{~mm}$. For plasma samples measured from 2012 to 2014 , the intra- and inter-assay coefficients were $9.71 \%$ and $11.01 \%$, respectively, and $6.18 \%$ and $10.29 \%$, respectively, for those analysed in 2015. For feather samples analysed between 2012 and 2014 intra- and inter-assay coefficients of variation were $7.03 \%$ and $8.83 \%$, respectively, whereas in 2015 samples, these values were respectively $8.82 \%$ and $12.45 \%$. These intra- and inter-assay coefficients of variation were determined by distributing a minimum of two duplicate samples of commercial rabbit plasma. Intra-assay coefficients of variation were calculating as the average of coefficients of variation of each assay. These coefficients were getting as the division of the standard deviation by the average value and multiplied by one hundred. The Inter-assay coefficients were calculating at the same way but getting the standard deviation and the average of all assays at the same time.

Statistical analysis

Analyses were fit using SAS 9.3 software (SAS Institute Inc., Cary, NC).

We estimated repeatability for the subset of individuals with repeated behavioural samples in different years by performing a linear mixed model following methods described in Nakagawa and Schielzeth (59), analysing variance component with the trait measure as the dependent variable and the individual ID as the random intercept. This allowed us to obtain among-individual variance and within-individual variance that are used to estimate repeatability following Lessells and Boag (60). A behaviour was considered as repeatable whenever among individual variance was significantly higher than within individual variance (i.e. $P<0.05$ ), which is a reasonably assumption given low repeatability of behavioural traits (see (61)). Non-repeatable behavioural traits were not considered in subsequent analyses based in one observation randomly selected per individual (55 males and 137 females).

General linear models were run to investigate the relationships between the individual colour morph and continuous behavioural traits (i.e. latency of response of males to territorial intruders, breath rate, latency to enter the next-box and feeding rates). Behavioural traits were entered in models as dependent variables and the colour score, the year (as a categorical variable with seven levels) and its interaction with colour morph were included as explanatory fixed terms. The date when the behavioural trait was measured was introduced in models as a covariate to account for possible variation in individual quality through the season. Also, we entered filming duration (in minutes) and filming 
time (minutes until sunset) as two further covariates in models of parental care (i.e. latency to enter the next-box and feeding rates) to control for their possible influence. In addition, we also included the colour morph of the mate as a fixed factor in the models to take into account the fact that the behaviour of a member of a couple could be modulated by the behaviour of its mate and hence by its plumage coloration. Finally, brood size was included as a further covariate in models as having large broods may change parental investment and several studies have shown a covariation between aggressiveness and increased parental investment (62-64).

In addition, a generalized linear model was used for analysing females' response to researchers as a binomial dependent variable (as proactive vs reactive). We replicated the same model structure than that for continuous behavioural traits, but included in the model the hour of the day (as time in minutes until sunset) when the response was measured and the interaction between colour morph and hour of the day as additional fixed factors to account for the fact that we captured females during the day at different hours and that females differing in colour may differ in activity rhythms along the day (see introduction).

We tested for differences in the levels of CORT in blood and feathers in relation to colour morph using General Linear Models. In a first analysis, stress-induced blood CORT of females was included as the dependent variable, the colour morph, the year and its interaction as fixed factors, and date and hour of the day as covariates. Hour was included to control for variations in CORT levels due to circadian rhythms (65). We also included the interaction between the colour morph and hour of the day to account for temporal variation in CORT levels associated to melanism (66). To analyse whether CORT in feathers differ with colour morph, we performed a model including sex, individual colour, year and the interactions as fixed factors.

Those models where colour scores explained variation in the behaviour and/or hormonal profiles of scops owls, were re-run including the colour morph (greyish vs reddish, excluding individuals of intermediate scores) as explanatory variable to address the specific roles of colour variation due to phaeomelanin (see above).

Standard model validation graphs (67) revealed that model assumptions of homogeneity of variance and normality of residuals were fulfilled after corticosterone in feathers and feeding rates and latency to return to nests were inverse-transformed, and log-transformed, respectively. $\mathrm{P}$ values smaller than 0.05 were considered significant. Given that the number of cases differed for the different explanatory variables in each model (i.e. we did not always capture the two adults in a nest or some of the individual measurements were not taken due to logistic problems (see table 1 appendix), besides saturated models we report reduced models based on backward stepwise procedure. Non-significant variables are left in the reduced models when they participated in a significant interaction. Pairwise differences in significant models were checked by comparisons of least-squared means of each treatment.

\section{Declarations}

Ethics approval and consent to participate

Animal data collection complies with the current laws of Spain and the fieldwork was authorized by Consejería de Medio Ambiente y Ordenación del Territorio de la Junta de Andalucía (projects CGL2011-27561/BOS and CGL2014-56769-P; license code: P06-RNM-01862). The study protocol was reviewed and approved by the ethical committee of the CSIC.

Consent for publication

Not applicable

Availability of data and materials

The datasets used and/or analysed during the current study are available from the corresponding author on reasonable request.

Competing interests

The authors declare that they have no competing interests.

Funding

This work was founded by Spanish Ministry of Economy and Competitiveness by the projects CGL2008-00718, CGL2011-27561, CGL201456769-P and CGL2017-83503-P. ACM was supported by the Spanish Ministry of Economy and Competitiveness (BES-2015-074948). DP was supported by the government of Extremadura (TA13002).

Authors' contributions 
JA and DP conceived and designed the study. AC, JA, ME and DP conducted fieldwork. ME and OC collaborated in hormonal analysis. AC, JA and DP analyzed the data and wrote the manuscript.

Acknowledgments

We thank people who helped us during fieldwork in the different years. Special thanks to the staff of the Centre d'Etudes Biologiques of Chizé. We acknowledge support of the publication fee by the CSIC Open Access Publication Support Initiative through its Unit of Information Resources for Research (URICI).

\section{References}

1. Gosling SD. From mice to men: What can we learn about personality from animal research? Psychological Bulletin. 2001;127(1):45-86.

2. Sih A, Bell AM. Insight for behavioral ecology from behavioral syndromes. Advances in the Study of Behavior. 2008;38(08):227-81.

3. Pigliucci M, Preston K. Phenotypic integration: studying the ecology and evolution of complex phenotypes. Vol. 1, Ecology Letters. Oxford and New York: Oxford University Press; 2004. 460 p.

4. Lande R, Arnold SJ. The Measurement of Selection on Correlated Characters. Evolution. 1983;37(6):1210.

5. Réale D, Reader SM, Sol D, McDougall PT, Dingemanse NJ. Integrating animal temperament within ecology and evolution. Biological Reviews. 2007;82(2):291-318.

6. Biro PA, Stamps JA. Are animal personality traits linked to life-history productivity? Trends in Ecology and Evolution. 2008;23(7):361-8.

7. Ducrest AL, Keller L, Roulin A. Pleiotropy in the melanocortin system, coloration and behavioural syndromes. Trends in Ecology and Evolution. 2008;23(9):502-10.

8. Fargallo JA, Velando A, López-Rull I, Gañán N, Lifshitz N, Wakamatsu K, et al. Sex-specific phenotypic integration: Endocrine profiles, coloration, and behavior in fledgling boobies. Behavioral Ecology. 2014;25(1):76-87.

9. Kim SY, Velando A. Phenotypic integration between antipredator behavior and camouflage pattern in juvenile sticklebacks. Evolution. 2015;69(3):830-8.

10. San-Jose LM, Ducrest AL, Ducret V, Simon C, Richter H, Wakamatsu K, et al. MC1R variants affect the expression of melanocortin and melanogenic genes and the association between melanocortin genes and coloration. Molecular Ecology. 2017;26(1):259-76.

11. Haase E, Ito S, Sell A, Wakamatsu K. Melanin Concentratioins in Feathers from Wild and Domestic Pigeons. Journal of Heredity. 1992;83(1):64-67.

12. Kimball RT. Hormonal conrol of coloration. In: McGraw KJ, editor. Bird coloration: mechanisms and measurements. Cambridge, U.K.: Harvard University Press; 2006. p. 137-200.

13. Jawor, Jodie and Breitwisch R. Melanin Ornaments, Honesty, and Sexual Selection. The Auk. 2003;120(2):249-65.

14. Roulin A. Covariation between plumage colour polymorphism and diet in the Barn Owl Tyto alba. Ibis. 2004;146(3):509-17.

15. Delhey K, Burger C, Fiedler W, Peters A. Seasonal changes in colour: A comparison of structural, melanin- and carotenoid-based plumage colours. PLoS ONE. 2010;5(7):e11582.

16. Galván I, Mousseau TA, Møller AP. Bird population declines due to radiation exposure at Chernobyl are stronger in species with pheomelanin-based coloration. Oecologia. 2011;165(4):827-35.

17. Meunier J, Pinto SF, Burri R, Roulin A. Eumelanin-based coloration and fitness parameters in birds: A meta-analysis. Behavioral Ecology and Sociobiology. 2011;65(4):559-567.

18. McGraw KJ, Wakamatsu K, Ito S, Nolan PM, Jouventin P, Dobson FS, et al. You Can'T Judge a Pigment By Its Color: Carotenoid and Melanin Content of Yellow and Brown Feathers in Swallows, Bluebirds, Penguins, and Domestic Chickens. The Condor. 2004;106(2):390.

19. McGraw KJ, Safran RJ, Wakamatsu K. How feather colour reflects its melanin content. Functional Ecology. 2005;19(5):816-21.

20. McGraw KJ. Mechanics of melanin-based coloration. In: Hill GE, McGraw KJ, editors. Bird coloration: mechanisms and measurements. Cambridge, U.K.: Harvard University Press; 2006. p. 243-94.

21. Costanzo A, Romano A, Ambrosini R, Parolini M, Rubolini D, Caprioli M, et al. Barn swallow antipredator behavior covaries with melanic coloration and predicts survival. Behavioral Ecology. 2018;29(6):1472-80.

22. Hubbard JK, Uy JAC, Hauber ME, Hoekstra HE, Safran RJ. Vertebrate pigmentation: from underlying genes to adaptive function. Trends in Genetics. 2010;26(5):231-9.

23. Roulin A, Emaresi G, Bize P, Gasparini J, Piault R, Ducrest AL. Pale and dark reddish melanic tawny owls differentially regulate the level of blood circulating POMC prohormone in relation to environmental conditions. Oecologia. 2011;166(4):913-21. 
24. Jenkins BR, Vitousek MN, Safran RJ. Signaling stress? An analysis of phaeomelanin-based plumage color and individual corticosterone levels at two temporal scales in North American barn swallows, Hirundo rustica erythrogaster. Hormones and Behavior [Internet]. 2013;64(4):665-72. Available from: http://dx.doi.org/10.1016/j.yhbeh.2013.08.006

25. Galván I, Solano F. Bird integumentary melanins: Biosynthesis, forms, function and evolution. International Journal of Molecular Sciences. 2016;17(4).

26. Abolins-Abols M, Kornobis E, Ribeca P, Wakamatsu K, Peterson MP, Ketterson ED, et al. Differential gene regulation underlies variation in melanic plumage coloration in the dark-eyed junco (Junco hyemalis). Molecular Ecology. 2018;27(22):4501-15.

27. Roulin A. and the handicap principle of sexual selection in melanin-based colouration. Biological Reviews. 2016;91(2):328-348.

28. Arai E, Hasegawa M, Makino T, Hagino A, Sakai Y, Ohtsuki H, et al. Physiological conditions and genetic controls of phaeomelanin pigmentation in nestling barn swallows. Behavioral Ecology. 2017;28(3):706-16.

29. Galván I. Physiological compartmentalization as a possible cause of phylogenetic signal loss: An example involving melanin-based pigmentation. Biological Journal of the Linnean Society. 2018;125(4):760-5.

30. Kosower NS, Kosower EM. The Glutathione Status of Cells. International Review of Cytology. 1978;54:109-60.

31. Galván I, Wakamatsu K, Camarero PR, Mateo R, Alonso-Alvarez C. Low-quality birds do not display high-quality signals: The cysteinepheomelanin mechanism of honesty. Evolution. 2015;69(1):26-38.

32. San-Jose LM, Roulin A. Toward Understanding the Repeated Occurrence of Associations between Melanin-Based Coloration and Multiple Phenotypes. The American Naturalist. 2018;192(2):111-30.

33. Robbins LS, Nadeau JH, Johnson KR, Kelly MA, Roselli-Rehfuss L, Baack E, et al. Pigmentation phenotypes of variant extension locus alleles result from point mutations that alter MSH receptor function. Cell. 1993;72(6):827-34.

34. Prota G. Melanins and melanogenesis. London, United Kingdom: Academic Press, Inc; 2012.

35. Ketterson ED, Atwell JW, Mcglothlin JW. Phenotypic integration and independence: Hormones, performance , and response to environmental change. Integrative and Comparative Biology. 2009;49(4):365-79.

36. Carere C, Groothuis TGG, Möstl E, Daan S, Koolhaas JM. Fecal corticosteroids in a territorial bird selected for different personalities: Daily rhythm and the response to social stress. Hormones and Behavior. 2003;43(5):540-8.

37. Kralj-Fišer S, Scheiber IBR, Blejec A, Moestl E, Kotrschal K. Individualities in a flock of free-roaming greylag geese: Behavioral and physiological consistency over time and across situations. Hormones and Behavior. 2007;51(2):239-48.

38. Schoech SJ, Rensel MA, Bridge ES, Boughton RK, Wilcoxen TE. Environment, glucocorticoids, and the timing of reproduction. General and Comparative Endocrinology. 2009;63(1-2):201-7.

39. Garamszegi LZ, Markó G, Herczeg G. A meta-analysis of correlated behaviours with implications for behavioural syndromes: Mean effect size, publication bias, phylogenetic effects and the role of mediator variables. Evolutionary Ecology. 2012;26(5):1213-1235.

40. Almasi B, Roulin A, Jenni-Eiermann S, Jenni L. Parental investment and its sensitivity to corticosterone is linked to melanin-based coloration in barn owls. Hormones and Behavior. 2008;54(1):217-23.

41. Almasi B, Jenni L, Jenni-Eiermann S, Roulin A. Regulation of stress response is heritable and functionally linked to melanin-based coloration. Journal of Evolutionary Biology. 2010;23(5):987-96.

42. Almasi B, Roulin A, Jenni L. Corticosterone shifts reproductive behaviour towards self-maintenance in the barn owl and is linked to melanin-based coloration in females. Hormones and Behavior [Internet]. 2013;64(1):161-71. Available from: http://dx.doi.org/10.1016/j.yhbeh.2013.03.001

43. Avilés JM, Cruz-Miralles Á, Ann S, Alexandre R, Kazumasa W, Deseada P. Redness variation in the Eurasian scops-owl otus scops is due to pheomelanin but is not associated with variation in the melanocortin-1 receptor gene (MC1R). Ardeola. 2020;67(1):3-13.

44. Parejo D, Cruz-Miralles Á, Rodríguez-Ruiz J, Expósito-Granados M, Avilés JM. Determinants of color polymorphism in the Eurasian scops owl Otus scops. Journal of Avian Biology. 2018;49(12):e01777.

45. Van Den Brink V, Dolivo V, Falourd X, Dreiss AN, Roulin A. Melanic color-dependent antipredator behavior strategies in barn owl nestlings. Behavioral Ecology. 2012;23(3):473-80.

46. Willie JT, Sinton CM, Maratos-Flier E, Yanagisawa M. Abnormal response of melanin-concentrating hormone deficient mice to fasting: Hyperactivity and rapid eye movement sleep suppression. Neuroscience. 2008;156(4):819-29.

47. Scriba MF, Henry I, Vyssotski AL, Mueller JC, Rattenborg NC, Roulin A. Ultradian Rhythmicity in Sleep-Wakefulness Is Related to Color in Nestling Barn Owls. Journal of Biological Rhythms. 2017;32(5):456-68.

48. Sapolsky RM, Romero LM, Munck AU. How do glucocorticoids influence stress responses? Integrating permissive, suppressive, stimulatory, and preparative actions. Endocrine Reviews. 2000;21(1):55-89. 
49. Korte SM, Koolhaas JM, Wingfield JC, McEwen BS. The Darwinian concept of stress: Benefits of allostasis and costs of allostatic load and the trade-offs in health and disease. Neuroscience and Biobehavioral Reviews. 2005;29(1 SPEC. ISS.):3-38.

50. Rodríguez J, Avilés JM, Parejo D. The value of nestboxes in the conservation of Eurasian Rollers Coracias garrulus in southern Spain. Ibis. 2011;153(4):735-45.

51. Cramp S. The complete birds of the western Palearctic. CD-ROM ver. Oxford University Press; 1998.

52. Parejo D, Avilés JM, Rodríguez J. Alarm calls modulate the spatial structure of a breeding owl community. Proceedings of the Royal Society B: Biological Sciences. 2012;279(1736):2135-41.

53. Del Hoyo J, Elliott A, Sargatal J. Handbook of the Birds of the World, : Barn-owls to Hummingbirds. Barcelona, Spain: Lynx Edicions; 1999.

54. Rodríguez-Ruiz J, Parejo D, de la Puente J, Valera F, Calero-Torralbo MA, Bermejo A, et al. Short- and long-term effects of tracking devices on the European Roller Coracias garrulus. Ibis. 2016;158(1):179-83.

55. Fucikova E, Drent PJ, Smits N, Van Oers K. Handling stress as a measurement of personality in great tit nestlings (parus major). Ethology. 2009;115(4):366-74.

56. Dingemanse NJ, Dochtermann NA. Quantifying individual variation in behaviour: Mixed-effect modelling approaches. Journal of Animal Ecology. 2013;82(1):39-54.

57. Bortolotti GR, Marchant TA, Blas J, German T. Corticosterone in feathers is a long-term, integrated measure of avian stress physiology. Functional Ecology. 2008;22(1):494-500.

58. Lormée H, Jouventin P, Trouve C, Chastel O. Sex-specific patterns in baseline corticosterone and body condition changes in breeding Redfooted Boobies Sula sula. Ibis. 2003;145(2):212-9.

59. Nakagawa S, Schielzeth H. Repeatability for Gaussian and non-Gaussian data: A practical guide for biologists. Biological Reviews. 2010;85(4):935-56.

60. Lessells CM, Boag PT. Unrepeatable Repeatabilities: A Common Mistake. 1987;104(1):116-21.

61. Bell AM, Hankison SJ, Laskowski KL. The repeatability of behaviour: a meta-analysis. Animal Behaviour. 2009;77(4):771-83.

62. Kontiainen P, Pietia H, Brommer JE. Aggressive Ural owl mothers recruit more offspring. Behavioral Ecology. 2009;20(4):789-796.

63. da Silva A, van den Brink V, Emaresi G, Luzio E, Bize P, Dreiss AN, et al. Melanin-based colour polymorphism signals aggressive personality in nest and territory defence in the tawny owl (Strix aluco). Behavioral Ecology and Sociobiology. 2013;67(7):1041-52.

64. Brommer JE, Karell P, Ahola K, Karstinen T. Behavioral Residual correlations, and not individual properties, determine a nest defense boldness syndrome. Behavioral Ecology. 2014;25(4):802-12.

65. Breuner CW, Wingfield JC, Romero LM. Diel rhythms of basal and stress-induced corticosterone in a wild, seasonal vertebrate, Gambel's white-crowned sparrow. Journal of Experimental Zoology. 1999;284(3):334-42.

66. Roulin A, Almasi B, Jenni L. Temporal variation in glucocorticoid levels during the resting phase is associated in opposite way with maternal and paternal melanic coloration. Journal of Evolutionary Biology. 2010;23(10):2046-53.

67. Zuur AF, leno EN, Walker NJ, Saveliev AA, Smith GM. Mixed effects models and extensions in ecology with R. New York, N.Y.:Statistics for Biology and Health; 2009.

68. Chang CM, Coville JL, Coquerelle G, Gourichon D, Oulmouden A, Tixier-Boichard M. Complete association between a retroviral insertion in the tyrosinase gene and the recessive white mutation in chickens. BMC Genomics. 2006;7:1-15.

69. Gunnarsson U, Hellström AR, Tixier-Boichard M, Minvielle F, Bed'hom B, Ito S, et al. Mutations in SLC45A2 cause plumage color variation in chicken and Japanese quail. Genetics. 2007;175(2):867-77.

70. Minvielle F, Bed'hom B, Coville JL, Ito S, Inoue-Murayama M, Gourichon D. The "silver" Japanese quail and the MITF gene: Causal mutation, associated traits and homology with the "blue" chicken plumage. BMC Genetics. 2010;11:1-7.

71. Lehtonen PK, Laaksonen T, Artemyev A V., Belskii E, Berg PR, Both C, et al. Candidate genes for colour and vision exhibit signals of selection across the pied flycatcher (Ficedula hypoleuca) breeding range. Heredity. 2012;108(4):431-40.

72. Karell P, Brommer JE, Ahola K, Karstinen T. Brown tawny owls moult more flight feathers than grey ones. Journal of Avian Biology. 2013;44(3):235-44.

73. Boerner M, Krüger O. Aggression and fitness differences between plumage morphs in the common buzzard (Buteo buteo). Behavioral Ecology. 2009;20(1):180-5.

74. Sternalski A, Bretagnolle V. Experimental evidence of specialised phenotypic roles in a mobbing raptor. Behavioral Ecology and Sociobiology. 2010;64(8):1351-1361. 
75. Figueiredo HF, Ulrich-Lai YM, Choi DC, Herman JP. Estrogen potentiates adrenocortical responses to stress in female rats. American Journal of Physiology - Endocrinology and Metabolism. 2007;292(4).

76. Rosvall KA, Bergeon Burns CM, Barske J, Goodson JL, Schlinger BA, Sengelaub DR, et al. Neural sensitivity to sex steroids predicts individual differences in aggression: Implications for behavioural evolution. Proceedings of the Royal Society B: Biological Sciences. 2012;279(1742):3547-55.

77. Burns CMB, Rosvall KA, Ketterson ED. Neural steroid sensitivity and aggression: Comparing individuals of two songbird subspecies. Journal of Evolutionary Biology. 2013;26(4):820-31.

78. Van den Brink V, Henry I, Wakamatsu K, Roulin A. Melanin-Based Coloration in Juvenile Kestrels (Falco tinnunculus) Covaries with AntiPredatory Personality Traits. Ethology. 2012;118(7):673-82.

79. Grunst AS, Grunst ML, Rotenberry JT. Sexual pigmentation and parental risk-taking in yellow warblers Setophaga petechia. Journal of Avian Biology. 2015;46(1):9-17.

80. Saino N, Canova L, Costanzo A, Rubolini D, Roulin A, Møller AP. Immune and Stress Responses Covary with Melanin-Based Coloration in the Barn Swallow. Evolutionary Biology. 2013;40(4):521-31.

\section{Figures}

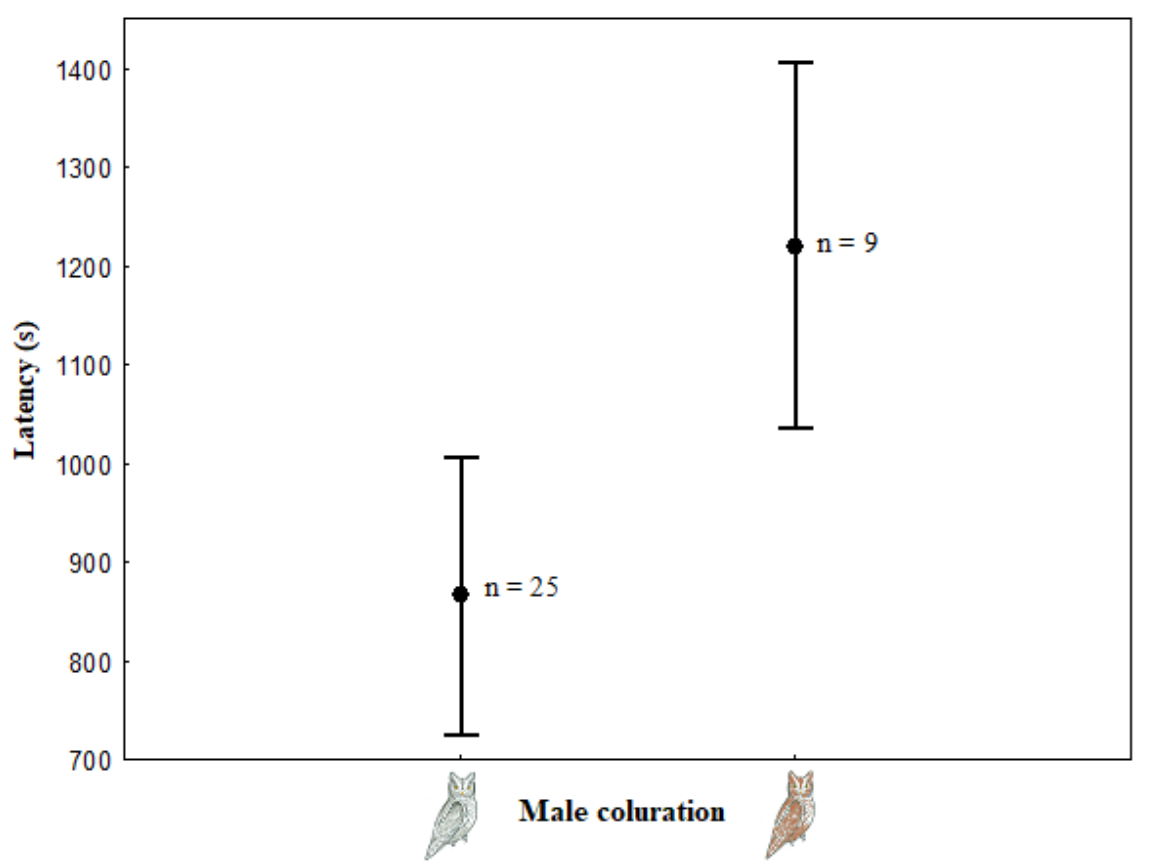

\section{Figure 1}

Latency to enter the nest-box (mean \pm SE) after setting the microcamera territories of male scops owls in relation to plumage coloration (as reddish versus greyish individuals). Sample sizes are shown close to the mean 


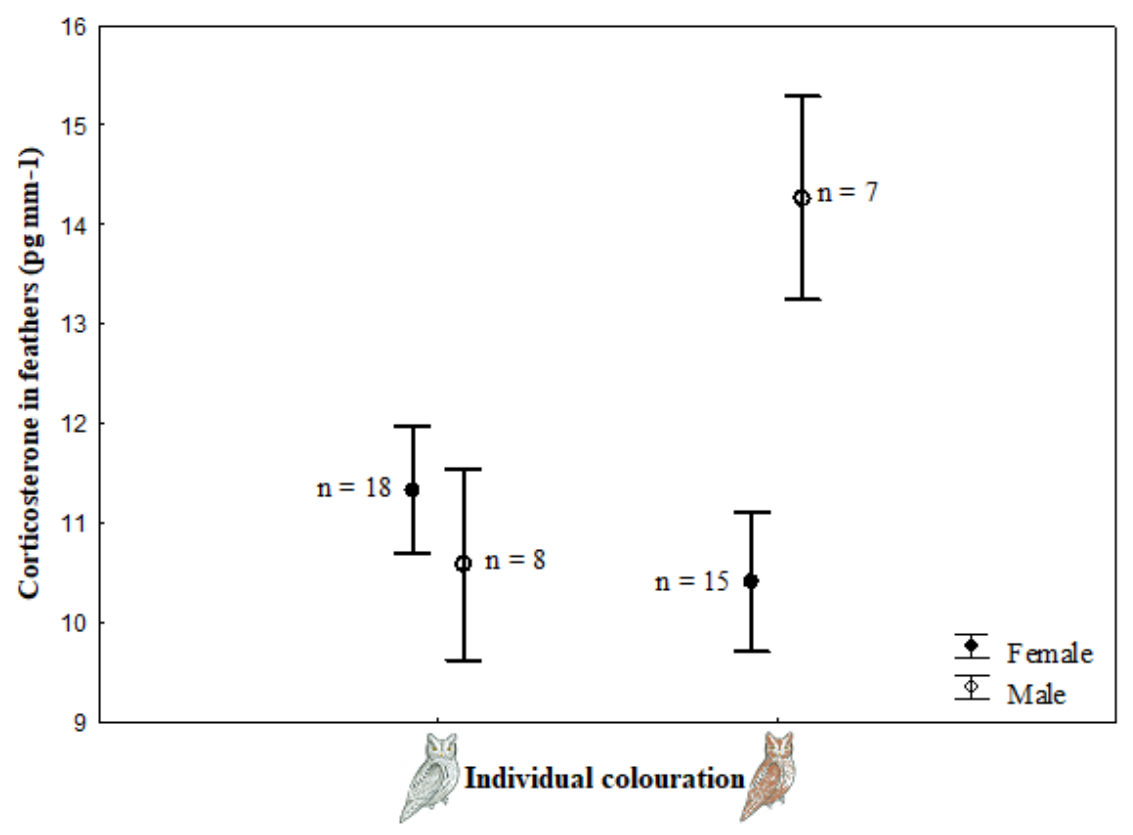

Figure 2

Levels of CORT in feathers (mean $\pm \mathrm{SE}$ ) in relation to plumage coloration (as reddish versus greyish individuals) for female and male scops owls. Sample sizes are shown close to the mean

\section{Supplementary Files}

This is a list of supplementary files associated with this preprint. Click to download.

- ESMFrontiersinZoology.docx 